\title{
Morphological and Physiological Traits of Assistance in the Selection of High Yielding Varieties of Durum Wheat (Triticum turgidum L. spp. Durum) for the Rainfed Mediterranean Environments of Central Chile
}

\section{Gerlitt González Ribot, Paola Silva, Edmundo Acevedo}

Facultad de Ciencias Agronómicas, Universidad de Chile, Santiago, Chile.

Email: gerlitt@gmail.com

Received September $16^{\text {th }}, 2012$; revised November $13^{\text {th }}, 2012$; accepted November $25^{\text {th }}, 2012$

\begin{abstract}
Chile has high potential to produce quality durum wheat; however, it is not self-sufficient. It is necessary to increase durum grain yield in the Mediterranean rainfed areas which are characterized by adverse environmental conditions, mainly, water deficit. The criteria normally used by breeders to select varieties of wheat for these environments are yield under stress and early flowering. The objective of this monograph is to propose that the selection of high yielding genotypes of durum wheat, under Chilean Mediterranean rainfed conditions, be assisted by morphological and physiological traits associated with yield in order to increase its heritability.
\end{abstract}

Keywords: Rainfed Mediterranean; Durum Wheat; Morphological; Physiological Traits

\section{Introduction}

Durum wheat is grown mainly for the production of pastas; durum wheat production in Chile covers only $50 \%$ of the needs of the local industry. The area cultivated to this crop in Chile has decreased, and it has also been displaced to rainfed areas where the yield is lower, since the irrigated zones are being used to grow fruit crops [1].

In recent decades there have been important changes in precipitation and increase in temperature throughout the world. The use of the soil has intensified and its degradation processes have exacerbated. The increase in temperature in Latin America by the end of the XXI century, according to different scenarios of climate change, will be between $1^{\circ} \mathrm{C}$ and $6^{\circ} \mathrm{C}$. The principal risk associated with the climatic changes being a scarcity of water due to drought and temperature increase. It has been estimated that during the decade of 2020 between 7 and 77 million people will suffer from lack of water due to climate change. Among the projections for Chile it is estimated that in the central and northern zones, considered to be areas with dry climates, the climate change may lead to a salinization and desertification of agricultural soils [2].

The majority of the Mediterranean climate in Chile, which is required to produce quality durum wheat, is located in the central zone. The industry demands both greater production and quality production. The zone with
Mediterranean climate is located between the IV and VIII Regions of the country [1]. This climate is characterized by winter rainfall and hot, dry summers, which submits the crop to a terminal drought stress [3]. To increase yield the genotypes for the low rainfall rainfed areas should have characters which maximize the capture of water from the soil, the transpiration in relation to evaporation, the transpiration efficiency and the harvest index $[4,5]$, thus the characters selected for this study must maximize the capture of water from the soil, decrease the direct evaporation of water from the soil, increase the transpiration efficiency and harvest index, and have a high heritability under drought.

About $50 \%$ of the yield under drought (Ys) is explained by the yield potential (Yp) of the genotype and its flowering date $(\mathrm{Fl})$; the remaining half of the regression sum of squares of $\mathrm{Ys}$ on $\mathrm{Yp}$ and $\mathrm{Fl}$ is the unexplained residual [6].

Although the majority of plant breeders use yield as the main criterion for the selection of varieties, yield has low heritability, especially under drought. Thus it has been proposed that the selection of genotypes for grain yield under these conditions should be assisted by characters associated with yield, and having greater heritability than yield [7-9]. These characters conform to an ideotype, a concept introduced by Donald [10]. Reynolds 
[11] in 2007 proposed an ideotype for bread wheat which includes a series of characters of use for the adaptation of wheat to drought [11].

Given that yield under stress has low heritability and an important unexplained residual remains using classical selection criteria (potential yield, yield under stress and flowering date), it is necessary to understand how much selection for yield in durum wheat may be improved when assisted by morphological and physiological characters. In this study we formulated the hypothesis that under conditions of water stress, by using selection for yield assisted by morphological and physiological characters, the selection efficiency in durum wheat will be improved compared to selection for yield and flowering date.

\section{Current Status of the Problem}

\subsection{Durum Wheat}

Hard or durum wheat (Triticum turgidum L. ssp. Durum) is a monocotyledonous annual species of the Poaceae (Graminae) used to obtain semolina for the production of pastas and pastas. Durum wheat is a tetraploid with $\mathrm{C} 3$ metabolism. There are wild diploid and tetraploid wheat varieties which have been widely used in genetic improvement. The cultivars are designated taxonomically as varieties of the species [12].

The pastas industry requires quality durum wheat (high protein, high vitrousness, gluten strength, amber color, among others), which is achieved by cultivating it in environments with hot, dry summers, characteristic of the Mediterranean climate. There are only 5 Mediterranean ecosystems in the world (California, Australia, South Africa, the Mediterranean Sea and Chile); in Chile this climate is found from $33^{\circ} \mathrm{S}$ to $37^{\circ} \mathrm{S}$ latitude (IV and VII Region, respectively [1].

\subsection{Crop Cycle}

In terms of phenology the crop cycle may be divided into three principal stages; vegetative, reproductive and grain filling. The first is called the vegetative stage because the apex is differentiating the primordia of vegetative structures (leaves). This stage begins with the re-activation of metabolism after imbibitions of the seed, and finalizes at floral initiation, that is, when the apex stops differentiating leaves and begins to differentiate spikelets, which may occur at any moment from emergence to advanced tillering, depending on the genotype and the environmental conditions. The second stage begins with floral initiation, called the reproductive stage, which extends until the differentiation of the terminal spikelet in the apex of the spike. With the formation of the primordium of the terminal spike the number of spikelets per spike is determined, this generally coincides with the end of tillering; when this occurs the tillers begin to die in the inverse order of their emergence. The maximum number of floral primordia occurs when jointing begins. From the boot stage onwards the majority degenerate, and only a few prosper to produce fertile flowering florets; this is the period in which the maximum of dry matter in the spike occurs during the pre-flowering stage. Meiosis finished in the boot stage of the crop the male and female gametes being mature, anthesis occurs approximately three days after the emergence of the spike. If there is water stress in the period of spike growth to flowering-beginning of grain filling, the grain set is notably affected. Finally, the stage of grain filling has two main periods, the grain set stage during which the number of endosperm cells is defined by an active cell division in the endosperm, followed by the period of effective grain filling, in which as well as accumulating dry matter in the grains, all the vegetative structures of the embryo are differentiated [13].

\subsection{Mediterranean Environment}

The term environment is related to the set of climate , soil, biotic factors (plagues and diseases) and the management conditions of a crop carried out in a given year (annual crops) or for various years (perennial crops). In particular, an environment identifies a situation in a year (annuals) or the situation of combined cycle crops (perennial) in the analysis of trials repeated over time [14]. The Mediterranean environment is characterized by humid, temperate winters in which the annual rains are concentrated, with precipitation between 250 and 1000 $\mathrm{mm}$. The dry season may last from 1 to 8 months; summers are dry and hot. The thermal regime clearly marks the seasons; the coldest month has a daily mean temperature which oscillates between $3^{\circ} \mathrm{C}$ and $18^{\circ} \mathrm{C}$, while the warmest month has a daily mean temperature which fluctuates from $14^{\circ} \mathrm{C}$ and $32^{\circ} \mathrm{C}$ [3]. In particular, the Mediterranean zone of central Chile has a temperate mesothermal stenothermic semi-arid Mediterranean climate. The annual variation in mean daily temperature ranges from a maximum of $28.7^{\circ} \mathrm{C}$ in January to a minimum of $3.4^{\circ} \mathrm{C}$ in July. It includes approximately 17 frosts per year; 1754 day-degrees per year; 1250 cold hours and a mean annual precipitation of $330 \mathrm{~mm}$ [15].

\subsection{Potential Yield}

The determination of the potential yield and the yield under stress of a genotype is one way to evaluate its adaptation. Potential yield is defined as the yield obtained by an adapted genotype under conditions of optimum management in the absence of biotic and abiotic stresses 
[16]. It is a parameter which allows the quantification of the reduction in yield caused by stress. A genotype with high potential yield decreases its yield when it is subjected to stress, and in environments with moderate stresses it can maintain a better yield than a genotype with low potential yield [16].

\subsection{Yield under Water Stress}

Water deficit is the stress that most reduces the growth and production of crops, because it involves all the physiological and chemical processes of the plant, has negative effects on transpiration, photosynthesis, respiration and metabolic reactions, and produces anatomical variations (growth, reproduction, fruit and seed development). In agronomic terms it results in a reduction in quantitative and qualitative yield, since it induces yield reduction as well as modifications in the chemical composition of foods [16]. All crops have a critical period which is more sensitive to drought, a stage in which the crop has the greatest growth and cell division, which generates in a brief period of time large changes in a production component of the plant. In the case of wheat this stage is from 20 - 30 days before anthesis to 10 days after anthesis [16]. In this stage the potential grain sink is being formed and the source is limiting, hence for greater yield the photosynthetic rate must be higher, as well as other aspects which assure a high number of grains per unit surface area to the crop [16].

The physiological changes produced by water stress begin with a decrease in cell elongation and a decrease in the growth of apices and roots. The inhibition of cell expansion is usually followed by a reduction in the synthesis of cell walls; protein synthesis is decreased. Water stress also reduces photosynthesis due to stomata closure and thus decreases the production and yield of crops. Under field conditions all plants are exposed to water stress at some point during their life cycle. Research and observations in arid zones has shown diverse morphological, physiological and ecological adaptations which allow plants to overcome or tolerate drought conditions [17].

Passioura, in 1977, analyzed yield under water stress using the equation

$$
\mathrm{Ys}=\mathrm{T} \times \mathrm{TE} \times \mathrm{HI}
$$

Where, Ys is yield under stress $\left(\mathrm{kg} \cdot \mathrm{ha}^{-1}\right), \mathrm{T}$ is transpiration $(\mathrm{mm})$, TE is transpiration efficiency $\left(\mathrm{kg} \cdot \mathrm{ha}^{-1} \cdot \mathrm{mm}^{-1}\right)$, and $\mathrm{HI}$ is the adimensional harvest index. It is evident that if the interaction among the terms of this identity is low or inexistent, yield under stress will be maximized by increasing any of the terms.

Figure 1 shows the positive relation existing among wheat yield vs. evapotranspiration in wheat, and shows

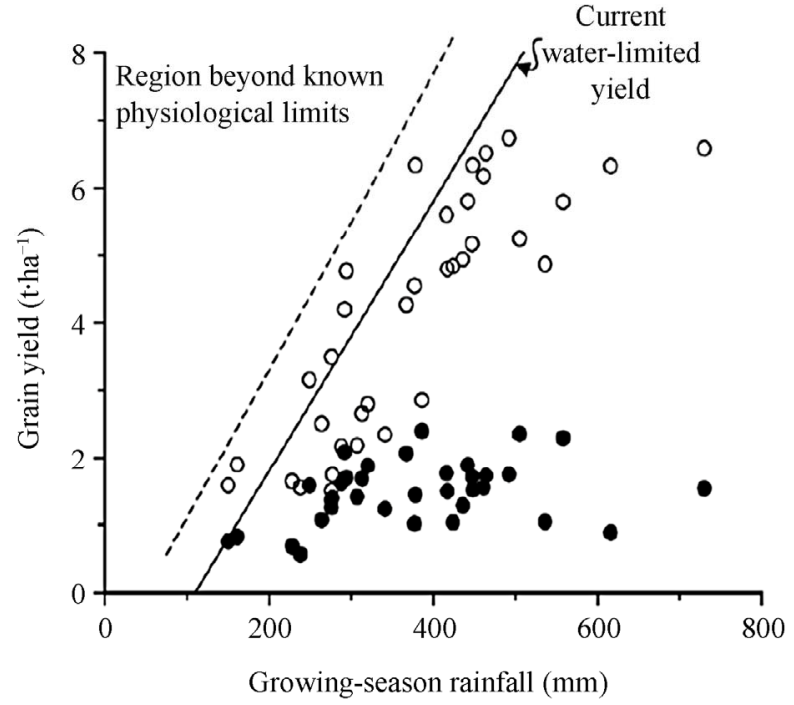

Figure 1. Mean wheat yields, reported (dark dot) and simulated (white dot) in Wagga Wagga from 1949 to 1983 in relation to evapotranspiration in the growing season. The solid diagonal is the maximum yield obtained per water evapotranspired and dotted line is the desired increase of the slope's solid diagonal [4].

how water availability limits yield. The solid diagonal line is the maximum yield obtained per water evaporated and transpired. The intersection with the $\mathrm{X}$ axis is the water lost by evaporation from the soil [4]. The realized yield is distributed from the diagonal line to the right; the region to the left of the diagonal line is outside the known physiological and agronomic limits. The diagonal slope represents the transpiration efficiency (TE). According to Figure 1, wheat genotypes which have characters that decrease direct water evaporation from the soil (which is generally high and may be greater than $50 \%$ of the precipitation) displace the base of the line towards the left [4]. Genotypes which have greater transpiration efficiency increase the slope of the diagonal. If this slope increases (dashed line in Figure 1), the potential yield in conditions of water limitation will be greater [4].

Comparing yield under drought (Ys) with potential yield (Yp) it is observed that approximately $50 \%$ of the yield under stress is explained by the potential yield of the genotype and its flowering date (FI) (scape of the stress), while half of the sum of squares of the regression of Ys on Yp and Fl remains as unexplained residuals [6]. Bidinger et al. in 1987 constructed an index with the residuals which they called the Drought Response Index (DRI), which allows an estimation of the sensitivity or resistance of a genotype to water stress once the effects of Yp and Fl on Ys have been discounted. This morphological index may be used as a criterion to select genotypes or morphological-physiological traits associated 
with it [6]. According to these authors, yield under drought conditions depends on the potential yield of the genotype, the flowering date (escape capacity) and the response of the genotype to water stress (DRI), represented by the equation.

$$
\mathrm{Ys}=\mathrm{Yp}+\mathrm{Fl}+\mathrm{DRI}
$$

Where, Ys is yield under stress, Yp is potential yield; $\mathrm{Fl}$ is days to flowering, and DRI is the drought resistance index.

\subsection{Crop Improvement}

The objectives of crop improvement fall into three categories. In the first group, known imperfections of the crop are corrected by eliminating the defective plants; for example if resistance to a disease is incorporated, susceptible plants are eliminated; this is called Elimination of Defects. In the second category falls the selection for higher yield. The third category is the selection of model plants or ideotypes [10].

\subsubsection{Ideotype}

Generally, plant breeders have in mind an ideal type of plant which would have all the characteristics that appear to be adequate to achieve maximum production in a given environment. The concept of the ideotype of a crop was introduced by Donald in 1968; he proposed that instead of selecting for yield and for elimination of defects only, an ideotype of plant with particular traits could be formulated to orient selection. He defined an ideotype of a crop as a model plant from which one would expect to have the greatest yield and grain quality (or any other useful product) when it grows in a defined environment [10].

\subsubsection{Morphological and Physiological Traits Adapted to Drought Associated to Yield}

Although the majority of plant breeders still use yield as the main criterion for the selection of varieties, yield has low heritability, especially under stress [7-9]. Thus it has been proposed that the selection of genotypes under stress conditions should be assisted by traits associated with yield, which generally have greater heritability and are less influenced by the environment [7-9]. Tables 1-5 show those traits with high heritability; they do not include traits with intermediate or low heritability [18].

Reynolds [11], in 2007 constructed an ideotype for bread wheat with characters of drought adaptation. He indicated characters for greater efficiency in water use such as low discrimination of ${ }^{13} \mathrm{C}$, photosynthesis in the spike and awns and high harvest index; characters of leaf anatomy and morphology such as pale green color, wax, pubescence, posture, undulations and presence of anti-
Table 1. Morphological traits for visual selection in an F2 populations in regions where drought limits yield.

\begin{tabular}{cccc}
\hline Traits & $\mathrm{H}$ & $\mathrm{G} \times \mathrm{E}$ & Environment \\
\hline Flowering date & High & Low & Specific \\
Glaucousness & High & Low & Universal \\
Awns & High & Low & Universal \\
Plant height & High & Low & Universal \\
Seed size & High & Intermedia & Universal \\
\hline
\end{tabular}

Where, $\mathrm{H}$ is Heritability, $\mathrm{G} \times \mathrm{E}$ is genotype per environment interaction, Universal is selection for all environments, and Specific is selection for an specific environment.

Table 2. Traits which increase soil water use.

\begin{tabular}{cccc}
\hline Traits & $\mathrm{H}$ & $\mathrm{G} \times \mathrm{E}$ & Environment \\
\hline Phenology & High & Low & Specific \\
Early vigor & High & Low & Specific \\
Tillering & High & Low & Specific \\
\hline
\end{tabular}

Table 3. Traits which improve plant establishment and early canopy development.

\begin{tabular}{cccc}
\hline Traits & $\mathrm{H}$ & $\mathrm{G} \times \mathrm{E}$ & Environment \\
\hline Long coleoptile & High & Low & Universal \\
Grain length & High & Low & Universal \\
Seedling with wide leaves & High & Low & Specific \\
Embryo size & High & Low & Specific \\
\hline
\end{tabular}

Table 4. Traits which increase transpiration efficiency.

\begin{tabular}{cccc}
\hline Traits & $\mathrm{H}$ & $\mathrm{G} \times \mathrm{E}$ & Environment \\
\hline Phenology & High & Low & Specific \\
Early vigor & High & Low & Specific \\
Isotopic ${ }^{13}$ C Discrimination & High & Low & Universal \\
Glaucousness & High & Low & Universal \\
Pubescence & High & Low & Universal \\
\hline
\end{tabular}

Table 5. Traits which increase harvest index.

\begin{tabular}{cccc}
\hline Traits & $\mathrm{H}$ & $\mathrm{G} \times \mathrm{E}$ & Environment \\
\hline Phenology & High & Low & Specific \\
Peduncule height and length & High & Low & Universal \\
Tillering & High & Low & Specific \\
\hline
\end{tabular}

oxidants; characters to obtain greater biomass prior to anthesis, including early vigor to cover the ground surface, long coleoptiles, large seed and the capacity to accumulate reserve carbohydrates in the stem; and characters related to the access of water such as relatively high leaf water content, low foliage temperature, osmotic adjustment and deep root system [11]. Reynolds emphasized that not all of these are useful in all drought envi- 
ronments [19].

The characters of the ideotype of interest to us are those associated with high yield having high heritability in drought environments and low genotype $\times$ environment interaction, which decrease direct evaporation of water from the soil and increase transpiration efficiency. Thus the characters we have chosen are flowering date, plant height, seed size, tillering, initial vigor, isotopic discrimination of ${ }^{13} \mathrm{C}$ and glaucousness and/or pubescence [18].

A number of researchers have studied one or more of these characters for wheat resistance to drought, includeing:

- Early flowering as conferring escape of terminal drought stress $[8,11,18,20]$.

- Plant height of $70-100 \mathrm{~cm}$ under stress $[18,21,22]$.

- Characters which decrease direct evaporation of water from the soil, increasing plant use of soil water [18], such as.

- Initial vigor, which increases ground cover and transpiration efficiency [11,18-20,23].

- Tillering, which increases ground coverage and provides a high number of spikes per square meter $[10$, $18,24,25]$.

Also, those characters favoring plant establishment and early canopy development, which also decrease direct evaporation of water from the soil [18], such as:

- Large seeds which have greater reserves to insure greater initial vigor $[11,18,19,26]$.

Traits that favor the water status of the crop by:

- A high discrimination of ${ }^{13} \mathrm{C}$ may be an excellent indicator of the water capture of a crop. More water capture signifies greater transpiration and greater ${ }^{13} \mathrm{C}$ discrimination [27]. Low isotopic discrimination of carbon 13 , on the other hand, may be of use since $\Delta{ }^{13} \mathrm{C}$ is negatively related to transpiration efficiency $[28,29]$.

- The pubescence and glaucousness of the leaves reduce water loss due to an increased layer of resistance to the movement of water vapor away from the leaf surface (pubescence) and to a favorable change of the energy balance of the leaf due to a greater albedo for short-wave radiation (glaucousness) $[8,11,24,25]$.

\subsubsection{Selection Efficiency}

Given that yield under stress has low heritability and an important unexplained residual remains using the classical selection criteria of potential yield, yield under stress and flowering date, it is necessary to know how much selection is improved when assisted by morphological and physiological traits. This may be approximated by defining the Selection Efficiency for a given trait or combination of traits [30], as in

$$
=\frac{\begin{array}{l}
\text { Selection Efficiency } \\
\text { Yield with Trait }(+)-\text { Yield with Trait }(-)
\end{array}}{10 \% \text { High Yield }-10 \% \text { Low Yield }}
$$

Where, Selection Efficiency is the capacity that a morpho-physiological trait has to explain variation in yield in the presence of all possible combinations of the other studied traits. Trait $(+)$ and Trait $(-)$ indicate the contrasting expression of each morphological or physiological trait in the presence of all possible combinations of the other studied traits. The 10\% High Yield is the mean yield of the $10 \%$ of the genotypes with greatest yield and the $10 \%$ Low yield is the mean yield of the $10 \%$ of genotypes with the lowest yield.

\subsubsection{Experience with Some of the Traits of the Proposed Ideotype in Plant Improvement Programs}

\subsubsection{Early Flowering}

Flowering time is an important trait related to the adaptation of genotypes to an area, especially in Mediterranean environments, affecting crop yield. This observation explains why flowering time is one of the first attributes optimized in plant improvement programs. The manipulation of flowering time may affect strongly the adaptation in regions with a Mediterranean climate, that is, in environments with hot, dry summers and with humid, temperate winters. In these environments, the vegetative phase and early flowering of the crop usually have an adequate availability of water. However, as the season advances, drought becomes more intense inducing water stress during the reproductive phase. After flowering, grain filling occurs under severe water and heat stress. The analysis of long-term tendencies of flowering time of cultivars released in various environments at different times shows that in the majority of cases there is little or no change in this trait in regions which do not have Mediterranean climate, although the reduction in flowering time has been a successful strategy to improve yield in environments with terminal stress [31]. This strategy has given good results, and earliness has probably been the most efficient way to increase yield in regions in which drought occurs during grain filling [31].

In an Italian study [32] it was observed that the genetic advance in grain yield of durum wheat was achieved by earlier flowering, increasing the number of grains per unit area and altering the pattern of senescence. This study compared yield without water deficit of six durum wheat cultivars released in the last 100 years. Although the modern genotypes flowered before the older varieties, there was no difference in the length of grain filling. The antiquity of the cultivars showed a highly significant negative correlation with the rate of grain filling $(r=$ 
$-0.91)$. Seed weight was associated with the rate of grain filling and with the number of grains per unit area. The study showed that in durum wheat, grain yield may be increased while preserving high grain weight by using flowering date as a character of indirect selection [32].

Historically, crop improvement programs of bread and durum wheat in INIA in Chile have released improved varieties based on yield and flowering date of each genotype [33,34].

\subsubsection{Plant Height}

The success in improvement of highly productive varieties has been due in part to selection for reduced height with a greater harvest index, especially when the reproductive organs, such as the grains of wheat, are the part of the plant of economic interest [35]. Barriga [35], evaluated in 1974 the main cultivars and lines of spring wheat in the south of Chile using the harvest index. He found a significant negative correlation between plant height and harvest index, indicating that the harvest index can be improved by decreasing plant height [35].

Zapata et al. [22] compared in 2004 near isogenic bread wheat lines which carried the dwarf genes Rht1 and/or Rht2 with a parent line that did not carry these genes (tall line) The semi-dwarf isolines $(60-100 \mathrm{~cm})$ had $21 \%$ higher yield than tall plants in all environments, while the tall line had only above-average yield in the poorest environments. The semi-dwarf isolines produced more biomass with highest harvest index $(\mathrm{p}<0.001)$, both in irrigated and rainfed conditions, which indicates a greater distribution of assimilates to the spikes and grains [22]. Figure 2 shows that semi-dwarf isolines were considered to be well-adapted to all the environments, because the slope of the regression line of genotype grain yield on environmental index was close to one and they had yield above the mean. The tall isoline had a lower

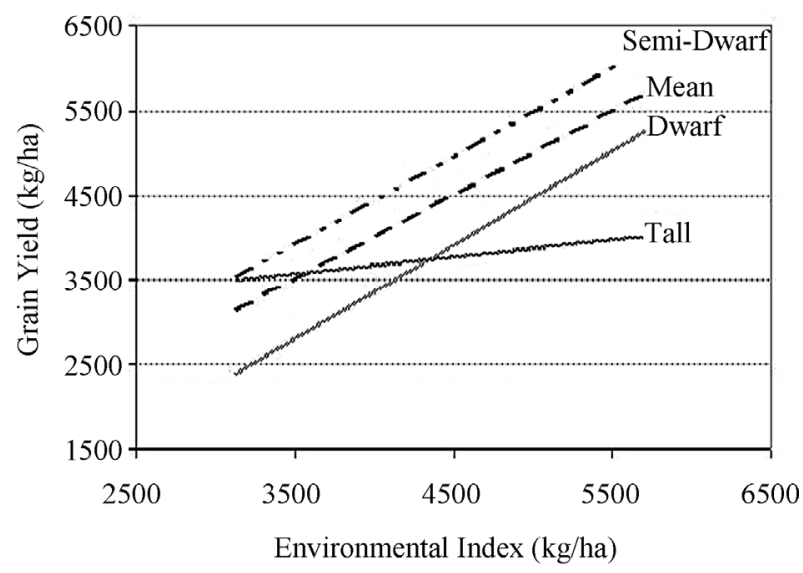

Figure 2. Yield stability of different groups of isolines. The environmental index is the mean yield of all genotypes at a given site [22]. slope, with less loss in yield moving from better to poorer environments (regression analysis slope 0.2), showing high stability and better adaptation to unfavorable environments. The dwarf isolines had the poorest yield in the worst environments. Although, the yield loss of genotypes with dwarfing genes was more pronounced when the environmental index decreased compared to the tall isoline, the semi-dwarf isolines maintained a greater absolute yield in the poorest environments, due to a greater potential yield associated with a greater harvest index and reduced height [22].

\subsubsection{Seed Size and Early Vigor}

An increase in early vigor may produce more rapid growth of deep roots and more adventitious roots in the upper part of the soil. The latter may be important for the absorption of water and nutrients before the losses by evaporation dry the upper part of the soil. Early vigor depends on various factors such as emergence speed, quantity and size of tillers, coleoptile length, length and width of seedling leaves and seed size. However, if seeding density is based on weight per unit surface, there may be little advantage in sowing larger seeds [18].

Lopez Castañeda et al. in 1996 showed that greater early vigor confers substantial benefits to rainfed Mediterranean crops [36]. They performed experiments to determine the important factors which may be responsible for the variation in early vigor in rye, bread wheat, durum wheat, triticale and oats; in all these crops embryo size was the most important factor to account for the differences in vigor among the species, accounting for $90 \%$ of the variation of vigor between species. Seed size within a species was proposed as an indirect estimation of early vigor, and may be used in an improvement program to increase the vigor of cereals [36]. This study also showed that early vigor of cereals may be increased by sowing larger seeds, because there was a linear increase in embryo size when larger seeds were sown. This is a simple management option, since larger seeds may be selected easily; thus seed size may be used for an indirect estimate of early vigor and used in an improvement program to increase the vigor of the cereals [36]. Smith et al. in 2003 also identified the seed size as the most determinant component of early vigor in Lolium perenne L., which correlated significantly $(\mathrm{p}<0.001)$ with leaf width (measured in the 3rd leaf) and with shoot length and width [37].

At least seven lines of rye $\left(\mathrm{F}_{6}\right)$ and seven lines of wheat $\left(\mathrm{F}_{6}\right)$ have been selected for high early vigor, drought resistance and grain yield in the Programa en Genética, Instituto de Recursos Genéticos y Productividad, Colegio de Postgraduados, Montecillo, Estado de México [38]. 


\subsubsection{Tillering}

Elhani et al. [25] in 2007 found that under conditions of terminal drought, cereal varieties with limited tillering had an advantage by having a lower number of nonproductive tillers, with limited water consumption before anthesis [25]. This study had four field trials in two growing seasons in southern Spain rainfed and irrigated. They studied 25 genotypes to evaluate the contribution of the main stem and tillers to grain yield and its components. They found significant differences among genotypes in these contributions in the absence of stress; however, the differences were not significant under water stress. In the irrigated trials the contribution of the main stem to grain yield was greater than that of the tillers (68\% vs. $32 \%$ ), and remained stable across years. However, in the rainfed trials, the main stem contributed differently according to the variation in climate between years. Thus in favorable conditions the contribution of the main stem to grain yield was greater than in the unfavorable year, $85 \%$ and $59 \%$, respectively. The grain yield of the main stem and the tillers depends upon the number of grains per spike, spikelets per spike and grain weight (MGW). In conditions of scarcity of water, the yield of the main stem depended upon the number of grains per spike and per spikelet, while the number of spikelets and MGW had less influence on the grain yield of the main stem. Genotypes with high tillering showed similar yield to genotypes with reduced tillering under water stress. Furthermore, there was no evidence of a positive or negative effect of the maximum number of tillers on grain yield in rainfed conditions. The number of tillers necessary to obtain high yields depends mainly on the environmental conditions [25].

The reduction of tillering in cereals has been proposed as advantageous under terminal drought, due to a decrease in the number of unproductive tillers which reduce the availability of water of the soil before anthesis [24]. Duggan et al. [24] in 2005 compared the yield of nearly isogenic wheat lines (Triticum aestivum L.) that did or not have the tillering inhibitor gene (tin). The effects of the tin gene were investigated in four pairs of nearly isogenic lines cultivated at two sowing densities in four localities of the wheat belt of eastern Austrailia during three years. All trials had terminal drought. The lines with greatest yield were those which had the tin gene; their yield was $5 \%$ greater than all the other lines. The tin gene decreased the number of fertile spikes by $11 \%$, increased the number of grains per spike by $9 \%$ and the grain weight by $2 \%$. The tin gene increased the mean harvest index by 0.02 and reduced the aerial biomass by $7 \%$. The increase in sowing density from 50 to $100 \mathrm{~kg} / \mathrm{ha}$ had little influence in yield or in the characters associated with yield, both with restricted tillering and in the free lines. There was interaction between sowing rate and the presence of the tin gene in yield; lines with the tin gene had $0.2 \mathrm{t} / \mathrm{ha}$ higher yield than the lines with free tillering in the higher seeding density, while there was no effect at the lower sowing rate. The response to nitrogen fertilization of various lines with the tin gene was also investigated at two sites. Nitrogen increased the number of spikes in all lines, but it was about $20 \%$ lower in the lines with the tin gene compared to the cultivars having free tillering. In the presence of terminal drought, with the greater nitrogen content, the yield of the wheat lines with the tin gene was $6 \%$ higher than their isogenic pairs. The concentration of grain proteins was not affected by the presence of the tin gene at the sites with high grain protein content, while at the sites with lowest grain protein content the tin gene had a positive effect [24].

\subsubsection{Isotopic Discrimination of Carbon 13}

Rebetzke et al. [39] in 2002 used the discrimination of the carbon 13 isotope $(\Delta)$ of wheat genotypes as an indirect selection criterion in $F_{2}$, evaluating the aerial biomass and grain yield in 30 genotypes with low $\Delta$ and 30 genotypes with high $\Delta$, in 9 environments with seasonal precipitation ranging from 235 to $437 \mathrm{~mm}$. Low $\Delta$ was significantly associated with greater grain yield, aerial biomass, harvest index and grain size, $5.8 \%, 2.7 \%, 3.3 \%$ and $4.8 \%$, respectively, than those with high $\Delta$ in all environments, while the number of grains was the same for low and high $\Delta$. Grain yield in the low $\Delta$ group increased significantly in environments with lower environmental index $(r=-0.89)$ with less total seasonal rainfall $(r=$ -0.85 ), indicating the benefit of low $\Delta$ and thus of high transpiration efficiency (TE) for genetic improvement of grain yield in environments with low precipitation. The heritability was much greater for $\Delta(\mathrm{h}=0.63)$ than for aerial biomass $(0.06)$ or grain yield $(0.14)$. There were strong genetic correlations of $\Delta$ with aerial biomass $(\mathrm{r}=$ $-0.61)$ and grain yield $(-0.58)$, suggesting that $\Delta$ could be used in indirect selection for TE in early generations. Selection of families with low $\Delta$ (high TE) for the advanced stages of the multiple environments studied should increase the probability of recovery of wheat families with greater yield in environments with water deficit [39].

\subsubsection{Leaf Glaucousness}

Richards et al. [40] suggested that there are many ways to improve TE genetically. For example, the increase in reflectance to reduce the temperature of the surface of the photosynthetic tissue increases TE. Indirect selection for glaucousness produces this result in cereals. Glaucousness, which is the visual manifestation of epicuticular wax, has been used to increase grain yield and dry mate- 
rial [40]. The epicuticular wax is the most external layer of smooth crystal wax which covers plant cuticles, and is composed of a complex of large-chain hydrophobic carbon compounds. Glaucousness is the visible opaquewhite or bluish-green wax which appears in plant cuticles; the color is the result of the $\beta$-diketone that the wax contains. Glaucousness increases light reflectance of the plant. The radiation absorbed (in the infrared and near infrared wavelengths) is reduced, which leads to a decrease in leaf temperature and to a difference in vapor pressure between the leaf and the environment [41]. Richards et al. in 1986 studied the development of epicuticular waxes in glaucous isogenic durum wheat and the probable causes of the increase in the yield of glaucous durum wheat and common wheat (Triticum aestivum L.) compared to their non-glaucous counterparts. Glaucousness first appears in the sheath of the flag leaf at the moment of stem elongation. It rapidly reaches its maximum expression, in the sheath of the flag leaf, in the abaxial surface of the lamina of the flag leaf and in the emerging apices. In greenhouse experiments, using pairs of isogenic lines of common and durum wheat, the efficiency of water use measured in droughted treatments from sowing to maturity was on the average $9 \%$ greater in the glaucous lines. Glaucous leaves retained water longer than non-glaucous leaves in the drought treatment but not with irrigation. In plants cultivated in the field in rainfed areas, the temperature of the photosynthetic tissues was up to $0.7^{\circ} \mathrm{C}$ lower in the glaucous lines, depending on the time of the day. Similarly, in well-watered greenhouse plants the organs of glaucous plants were on the average $0.3^{\circ} \mathrm{C}$ lower than in non-glaucous plants. Studies of gas exchange in durum wheat lines in the irrigated and drought greenhouse treatments indicated that the spikes of non-glaucous plants had greater rates of photosynthesis and transpiration, greater stomatal conductance and greater increase in photosynthetic rate with increased light. The relation between photosynthesis and transpiration was greater in the spikes of glaucous plants. This study showed that glaucousness may be a positive character for yield under conditions of water limitation, mainly due to its effect on efficient water use, from the moment the wax is deposited [40].

\subsubsection{Molecular Markers}

The combination of classical methods of genetic improvement with molecular techniques of genome analysis opens a new perspective for increasing genetic knowledge and the acceleration of crop improvement programs, since they decrease the time of phenotypic analysis by identifying the genotype directly [42]. This may be achieved using a diagnostic system based on segregation of molecular markers together with that of the genes of interest. According to Ferreira [42], a molecular marker is defined as any molecular phenotype originated by the expression of a gene, as in the case of isoenzymes or specific DNA segments (expressed or non-expressed regions of the genome). Markers allow the quantification of the existing genetic variability at the level of a DNA sequence and its correlation with phenotypic expression in procedures of genetic mapping; the information generated is then integrated with the methods of selection and recombination of genotypes as an additional tool to promote genetic advance. There are a large number of mapping studies in the literature of molecular markers, but there are few examples of the utilization of this technology in the generation of improved materials [42]. The scarcity of physiological and molecular studies in plants is one of the limits for the identification of the genes responsible for mechanisms of tolerance to environmental stress [43]. The available genetic information for important agronomic characteristics and quality in durum wheat grains is scarce compared to other cereals, thus it is necessary to obtain it to aid programs of genetic improvement. Selection assisted by molecular markers is more useful in improvement of characters governed by genes which are highly affected by the environment (low heritability). ICARDA is currently studying the potential use of selection assisted by markers of drought tolerance and grain quality by the accumulation of QTLs for drought and yield of durum wheat. In this durum wheat program the link between characters of drought resistance and grain quality is being studied with molecular markers (RFLP, SSR and AFLP). Molecular markers have been found to be associated with grain yield under drought and some morpho-physiological characters related to drought tolerance such as isotopic ${ }^{13} \mathrm{C}$ carbon discrimination, canopy temperature, chlorophyll inhibittion and proline content [1].

\section{Discussion}

Even though there are some discrepancies, the literature indicates that there is sufficient evidence of the positive effect of some morphophysiological characters (flowering date, plant height, seed size, early vigor, tillering, isotopic discrimination of carbon 13, leaf glaucousness) to use them in the indirect selection of varieties of durum wheat for rainfed Mediterranean environments and thus increase selection efficiency [22,31-36,39,40]. In particular, the Mediterranean rainfed area of central Chile has different degrees of drought [37-40], thus improvement for yield is made difficult due to its low heritability, and indirect characters may be beneficial. The literature indicates that the presence of these drought resistance characters in a variety provides it with the capacity to have a better yield under water stress. Additionally, these 
characters have two conditions which are convenient for improvement programs; they have high heritability and are easy to measure, which makes them useful for selection in early generations. This conventional method of improvement assisted by characters may also be complemented by molecular markers at different stages, to analyze the genetic diversity, select progenitors and identify varieties, depending upon their difficulty and cost. Since the characters recommended in this study are easy to measure and have high heritability the use of molecular markers would not be necessary, since the efficient use of molecular markers is obtained when selected characters are highly influenced by the environment; however, molecular markers could be useful if one wishes to accumulate various characters in the same cultivar [1].

This study provides a combination of characters for resistance to terminal drought, which conform an ideotype of durum wheat for the conditions of Mediterranean rainfed areas of the central zone of Chile. The combination of the proposed characters will provide the selected varieties with the capacity to produce more than others which do not possess them under these conditions. The literature demonstrates that the characters of the ideotype presented here would not affect the potential yield, with the exception of a low discrimination of ${ }^{13} \mathrm{C}$. Although this last character is negatively related to transpiration efficiency (with low discrimination there is higher transpiration efficiency), it is positively related to the capture of water by a genotype under stress conditions. Its use in plant improvement in one or the other direction will depend on the problem at hand. Under stress conditions, a low discrimination of carbon 13 may be due to a partial closure of stomata which generates an increase in the partial pressure of $\mathrm{CO}_{2}$ in intracellular spaces, and/or to a low discrimination of Rubisco against ${ }^{13} \mathrm{C}$. However, under potential conditions in which the partial closure of stomata due to low water availability does not exist, a low discrimination of ${ }^{13} \mathrm{C}$ is only attributable to a high rate of carboxylation of a Rubisco which is less capable of discriminating against ${ }^{13} \mathrm{C}$, making greater use of the available carbon. This analysis leads us to conclude that the best selection for this character should be made under potential conditions, if we want to assure that the genotype has a more efficient Rubisco, but it should be used under drought if the trait is used to select genotypes that make a better use of water available for transpiration.

Since there are molecular techniques which allow selection to be made in early generations $\left(\mathrm{F}_{2}\right)$, an improvement program could be designed which combines the three selection methods (selection assisted by morphophysiological characters, selection assisted by molecular markers and conventional selection). The elite material would be identified with best yield under opti- mal conditions and by means of a program of backcrosses, making the necessary number of backcrosses to incorporate the desired drought resistance characters to a genotype with high yield. The form of improvement for drought conditions has traditionally been multisite and multi-year trials; however, since this may currently be assisted using these characters which have a positive effect on yield under drought, our focus is on trying to incorporate them to genotypes with high potential yield and adapted to one site. The traditional system of multisite trials at one time played an important role, when the current tools were not yet available. The predictions of climate change and the changes which are already occurring show that the current need is for improvement in drought resistance.

A subject that has not been discussed in this article is the level of appearance of the morpho-physiological traits under study. Generally in a nursery, there are genotypes showing different intensities of the suggested traits, therefore the combination of the best selection intensity will be strongly dependent on the available genetic material. On the other hand if the purpose is to incorporate these traits in an adapted genetic material having high yield potential, we do not foresee interaction between the traits and their effect on yield under drought should be essentially additive.

\section{Conclusion}

There are morphological and physiological characters with high heritability and easy to measure in cereals which confer resistance to drought to wheat in Mediterranean rainfed areas, which may be used to assist in the selection of varieties of durum wheat in Chile. Among those which stand out due to their high heritability are flowering date, plant height, seed size, initial vigor, tillering, isotopic discrimination of carbon 13 and leaf glaucousness.

\section{Acknowledgements}

During several years the work of the author on this topic has been supported by CONICYT (Comisión Nacional de Investigación Científica y Tecnológica de Chile).

\section{REFERENCES}

[1] E. Acevedo and P. Silva, "Trigo Candeal Calidad, Mercado y Zonas de Cultivo," Facultad de Ciencias Agronómicas, Universidad de Chile, Chile, 2007.

[2] D. Dumas and Y. Kakabadse, "Cambio Climático y Pobreza en América Latina y el Caribe Consulta Regional," Informe Presentado por la Fundación Futuro Latino-americano al Centro Internacional de Investigaciones Para el Desarrollo (IDRC) y el Departamento 
Para el Desarrollo Internacional del Reino Unido (DFID), Futuro Latinoamericano, Diálogo, Capacidades y Desarrollo Sostenible, Quito, 2008.

[3] E. Acevedo, P. Silva, H. Silva and B. Solar, "Wheat Production in Mediterranean Environments," In: E. H. Satorre and G. A. Slafer, Eds., Wheat Ecology and Physiology of Yield Determination, The Haworth Press, Inc. New York, 1999. pp. 295-331.

[4] J. B. Passioura, "Increasing Crop Productivity When Water is Scarce-From Breeding to Field Management," Agricultural Water Management, Vol. 80, No. 1-3, 2006, pp. 176-196. doi:10.1016/j.agwat.2005.07.012

[5] J. B. Passioura, "Grain Yield, Harvest Index and Water Use of Wheat," Journal of the Australian Institute of Agricultural Science, Vol. 43, 1977, pp. 117-120.

[6] F. R. Bidinger, V. Mahalakshmi and G. D. P. Rao, "Assessment of Drought Resistance in Pearl Millet [Pennisetum americanum (L.) Leeke]. I. Factors Affecting Yields Under Stress," Australian Journal of Agricultural Research, Vol. 38, No. 1, 1987, pp. 37-48.

[7] E. Acevedo, "Improvement of Winter Cereal Crops in Mediterranean Environments: Use of Yield, Morphological and Physiological Traits," In: E. Acevedo, A. P. Conesa, P. Monneveux and P. Srivastava, Eds., Physiology Breeding of Winter Cereals for stressed Mediterranean Environments, INRA, Montpellier, 1991, pp. 273-305.

[8] S. A. Quarrie, J. Stojanović and S. Pekić, "Improving Drought Resistance in Small-Grained Cereals: A Case Study, Progress and Prospects," Plant Growth Regulation, Vol. 29, No. 1, 1999, pp. 1-21. doi:10.1016/j.agwat.2005.07.012

[9] C. McIntyre, K. Mathews, A. Rattey, S. Chapman, J. Drenth, M. Ghaderi, M. Reynolds and R. Shorter, "Molecular Detection of Genomic Regions Associated with Grain Yield and Yield-Related Components in an Elite Bread Wheat Cross Evaluated under Irrigated and Rainfed Conditions," TAG Theoretical and Applied Genetics, Vol. 120, No. 3, 2010, pp. 527-541. doi:10.1016/j.agwat.2005.07.012

[10] C. M. Donald, "The Breeding of Crop Ideotypes," Euphytica, Vol. 17, No. 3, 1968, pp. 385-403. doi:10.1016/j.agwat.2005.07.012

[11] M. Reynolds, "Trigo Que Utiliza el Agua de Manera Eficiente y Produce Grano de Buena Calidad," In: CIMMYT, Ed., Informe Annual del CIMMYT 2006-2007: Sembrar Innovación … Nutrir la Esperanza, CIMMYT, México City, 2007, pp. 14-15.

[12] FAO, "Aspectos Técnicos que Intervienen en la Elaboración de una Lista de Cultivos para el Sistema Multilateral en el Marco del Compromiso Internacional Revisado," 1998.

http://www.fao.org/nr/cgrfa/cgrfa-meetings/cgrfa-comm/f ifth-extra/es/.

[13] G. A. Slafer, D. J. Miralles, R. Savin, E. M. Whitechurch and F. G. González, "Ciclo Ontogénico, Dinámica del Desarrollo y Generación del Rendimiento y la Calidad en Trigo," In: E. H. Satorre, R. L. Benech, G. A. Slafer, E. B. de la Fuente, D. J. Miralles, M. E. Otegui and R. Savin, Eds., Producción de Granos: Bases Funcionales para su Manejo, Editorial Facultad de Agronomía, Universidad de Buenos Aires, Buenos Aires, 2003. pp. 101-132.

[14] P. Annicchiarico, "Genotype x Environment InteractionsChallenges and Opportunities for Plant Breeding and Cultivar Recommendations. (FAO Production and Protection Paper; 174)," Food and Agriculture Organization of the United Nations, Rome, 2002.

[15] F. Santibañez and J. M. Uribe, "Atlas Agroclimático de Chile: Regiones V y Metropolitana," Departamento de Ingeniería y Suelos, Fondo Nacional de Desarrollo Científico Y Tecnológico, Universidad de Chile, Santiago de Chile, 1990.

[16] J. P. Sanmartín and E. Acevedo, "Temperatura de Canopia, CWSI y Rendimiento en Genotipos de Trigo", Laboratorio de Relación Suelo-Agua-Planta, Facultad de Ciencias Agronómicas, Universidad de Chile, Santiago de Chile, 2001.

[17] R. Muñoz and E. Acevedo, "Evaluación del Rendimiento Potencial y Bajo Estrés Hídrico de 11 Genotipos de Quínoa (Chenopodium quinoa Willd)," Ingeniero de Ejecución Agrícola, Universidad Arturo Prat, Iquique, 2001.

[18] R. A. Richards, A. G. Condon and G. J. Rebetzke, "Traits to Improve Yield in Dry Environments," In: M. P. Reynolds, J. I. Ortiz-Monasterio and A. McNab, Eds., Application of Physiology in Wheat Breeding, CIMMYT, Mexico City, 2001. pp. 88-100.

[19] M. P. Reynolds, S. Rubeena and R. Trethowan, "Using "Smart" Physiological-Trait Based Crossing Strategies to Accumulate Drought-Adaptive Genes," In: P. Poland, M. Sawkins, J. Ribaut and D. Hoisington, Eds., Resilient Crops for Water Limited Environments: Proceedings of a Workshop Held at Cuernavaca, CIMMYT, Mexico City, 2004. pp. 185-187.

[20] E. Acevedo and S. Ceccarelli, "Role the PhysiologistBreeder in a Breeding Program for Drought Resistance Conditions," In: F. W. G. Baker, Ed., Drought Resitance in Cereal, C.A.B International, Wallingford, 1989. pp. 117-139.

[21] R. A. Fisher, "Selection Traits for Improving Yield Potential,” In: M. P. Reynolds, J. I. Ortiz-Monasterio and A. McNab, Eds., Application of Physiology in Wheat Breeding, CIMMYT, Mexico City, 2001. pp. 148-159.

[22] C. Zapata, P. Silva and E. Acevedo, "Comportamiento de Isolíneas de Altura en Relación con el Rendimiento y Distribución de Asimilados en Trigo", Agricultura Técnica, Vol. 64, No. 2, 2004, pp. 139-155.

[23] J. T. Ritchie, "Model for Predicting Evaporation from a Row Crop with Incomplete Cover", Water Resources Research, Vol. 8, No. 5, 1972, pp. 1204-1213. doi:10.1029/WR008i005p01204

[24] B. L. Duggan, R. A. Richards, A. F. van Herwaarden and N. A. Fettell, "Agronomic Evaluation of a Tiller Inhibition Gene (Tin) in Wheat. I. Effect on Yield, Yield Components, and Grain Protein," Australian Journal of Agricultural Research, Vol. 56, No. 2, 2005, pp. 169-178. 
doi:10.1071/AR04152

[25] S. Elhani, V. Martos, Y. Rharrabti, C. Royo and L. F. García del Moral, "Contribution of Main Stem and Tillers to Durum Wheat (Triticum turgidum L. var. Durum) Grain Yield and Its Components Grown in Mediterranean Environments," Field Crops Research, Vol. 103, No. 1, 2007, pp. 25-35. doi:10.1016/i.fcr.2007.05.008

[26] V. O. Sadras, "Evolutionary Aspects of the Trade-Off between Seed Size and Number in Crops," Field Crops Research, Vol. 100, No. 2-3, 2007, pp. 125-138. doi:10.1016/j.fcr.2006.07.004

[27] A. Blum, "Plant Breeding for Water-Limited Environments," Springer Science + Business Media, LLC, New York, 2011

[28] E. Acevedo, C. Baginsky, B. Solar and S. Ceccarelli, "Discriminación Isotópica de ${ }^{13} \mathrm{C}$ y su Relación con el Rendimiento y la Eficiencia de Transpiración de Genotipos Locales y Mejorados de Cebada Bajo Diferentes Condiciones Hídricas," Investigación Agrícola, Chile, Vol. 17, No. 1-2, 1997, pp. 41-54.

[29] P. Monneveux, D. Rekika, E. Acevedo and O. Merah, "Effect of Drought on Leaf Gas Exchange, Carbon Isotope Discrimination, Transpiration Efficiency and Productivity in Field Grown Durum Wheat Genotypes," Plant Science, Vol. 170, No. 4, 2006, pp. 867-872. doi:10.1016/j.plantsci.2005.12.008

[30] E. Acevedo, "Increasing the Yield Potential of Irrigated Bread Wheat. Wheat Special Report No.12," CIMMYT, Mexico City, 1992.

[31] J. L. Araus, G. A. Slafer, C. Royo and M. D. Serret, "Breeding for Yield Potential and Stress Adaptation in Cereals," Critical Reviews in Plant Sciences, Vol. 27, No. 6, 2008, pp. 377-412. doi:10.1080/07352680802467736

[32] R. Motzo, F. Giunta and G. Pruneddu, "The Response of Rate and Duration of Grain Filling to Long-Term Selection for Yield in Italian Durum Wheats", Crop and Pasture Science, Vol. 61, No. 2, 2010, pp. 162-169. doi:10.1071/CP09191

[33] M. Mellado, "El Trigo en Chile. Cultura, Ciencia y Tecnología. (Colección Libros INIA; 21) ," Centro Regional de Investigación Quilamapu, Chillán, 2007.

[34] M. Mellado and R. Madariaga, "Mejoramiento Genético del Trigo: Análisis del Periodo 1964-1994. (Serie Quilamapu; 70)," Centro Regional de Investigaciones
Quilamapu, Chillán, 1996.

[35] P. Barriga, "Índice de Cosecha en Trigo de Primavera," Agro sur, Vol. 2, No. 1, 1974, pp. 17-20.

[36] C. López-Castañeda, R. A. Richards, G. D. Farquhar and R. E. Williamson, "Seed and Seedling Characteristics Contributing to Variation in Early Vigor among Temperate Cereals", Crop Science, Vol. 36, No. 5, 1996, pp. 1257-1266. doi:10.2135/cropsci1996.0011183X003600050031x

[37] K. F. Smith, N. M. McFarlane, V. M. Croft, P. J. Trigg and G. A. Kearney, "The Effects of Ploidy and Seed Mass on the Emergence and Early Vigour of Perennial Ryegrass (Lolium perenne L.) Cultivars," Australian Journal of Experimental Agriculture, Vol. 43, No. 5, 2003, pp. 481-486. doi:10.1071/EA01130

[38] M. C. Castañeda, C. López-Castañeda, J. Molina, T. B. Colinas and A. Livera, "Crecimiento y Desarrollo de Cebada y Trigo," Revista Fitotecnia Mexicana, Vol. 27 No. 2, 2004, pp. 167-175.

[39] G. J. Rebetzke, A. G. Condon, R. A. Richards and G. D. Farquhar, "Selection for Reduced Carbon Isotope Discrimination Increases Aerial Biomass and Grain Yield of Rainfed Bread Wheat," Crop Science, Vol. 42, No. 3, 2002, pp. 739-745. doi:10.2135/cropsci2002.7390

[40] R. A. Richards, H. M. Rawson and D. A. Johnson, "Glaucousness in Wheat: Its Development and Effect on Water-Use Efficiency, Gas Exchange and Photosynthetic Tissue Temperatures," Functional Plant Biology, Vol. 13, No. 4, 1986, pp. 465-473. doi:10.1071/PP9860465.

[41] O. Merah, E. Deléens, I. Souyris and P. Monneveux, "Effect of Glaucousness on Carbon Isotope Discrimination and Grain Yield in Durum Wheat," Journal of Agronomy and Crop Science, Vol. 185, No. 4, 2000, pp. 259-265. doi:10.1046/j.1439-037x.2000.00434.x

[42] M. E. Ferreira and D. Grattapaglia, "Introduccuion al uso de Marcadores Moleculares en en Analisis Genetico," EMBRAPA-CENARGEN, Brasilia, 1998.

[43] M. Gidekel, A. Gutierrez, L. Barrientos, R. Herrera and H. Campos, "Métodos en Biología Molecular Vegetal. First International INIA Carillanca Workshop and Course on Plant Biotechnology. (Serie Acta; 1)," Instituto de Investigaciones Agropecuarias, Centro Regional de Investigación Carillanca, Temuco, 1999. 